\title{
Comparative in Vitro Studies of the Metabolism of Six 4-Substituted Methamphetamines and Their Inhibition of Cytochrome P450 2D6 by GC-MS with Trifluoroacetyl Derivatization
}

\author{
Masashi Taniguchi ${ }^{12^{*}}$, Yoshio Yamamoto ${ }^{3}$, Katsuji Nishi ${ }^{2}$ \\ ${ }^{1}$ Forensic Science Laboratory, Shiga Police Headquarters, Otsu, Japan \\ ${ }^{2}$ Department of Legal Medicine, Shiga University of Medical Science, Otsu, Shiga \\ ${ }^{3}$ Laboratory of Environmental Chemistry, Iga Research Institute of Mie University, Mie, Japan \\ Email: ${ }^{*}$ tanimasa@belle.shiga-med.ac.jp
}

Received March 5, 2013; revised March 21, 2013; accepted April 18, 2013

Copyright (C) 2013 Masashi Taniguchi et al. This is an open access article distributed under the Creative Commons Attribution License, which permits unrestricted use, distribution, and reproduction in any medium, provided the original work is properly cited.

\begin{abstract}
Use of new amphetamine-type stimulants (ATS) as designer drugs is a serious problem worldwide. ATS are used in tablet, capsule, and powder forms, and can be mixed with other drugs. There is little information available on how these new drugs are metabolized or their ability to inhibit the metabolism of co-administered drugs. This study aimed to investigate the metabolism of six 4-substituted analogs of methamphetamine (MA), and their potential inhibition of MA metabolism. The metabolism of MA and the 4-substituted MAs was examined in vitro using human metabolic enzymes. Metabolite analyses were performed using trifluoroacetyl derivatization and GC-MS. The experiments showed that cytochrome P450 2D6 (CYP2D6) was involved in the major metabolic pathway of MA, where it catalyzed $N$-demethylation of 4-fluoromethamphetamine (4-FMA), 4-chloromethamphetamine (4-CMA), 4-bromomethamphetamine (4-BMA), 4-iodomethamphetamine (4-IMA) and 4-nitromethamphetamine (4-NMA), and O-demethylation of 4-methoxymethamphetamine (4-MMA). The half maximal inhibitory concentration $\left(\mathrm{IC}_{50}\right)$ values for CYP2D6 using MA as substrate were different for each of the 4-substituted MAs. The strongest inhibitors of amphetamine production from MA were, in order, 4-IMA, 4-BMA, 4-CMA, 4-MMA, 4-FMA, and 4-NMA. The same order was observed for the $\mathrm{IC}_{50}$ values for inhibition of $p$-hydroxymethamphetamine production from MA, except for the $\mathrm{IC}_{50}$ of 4-MMA. The $\mathrm{IC}_{50}$ values of 4-IMA were lower than the $\mathrm{IC}_{50}$ values of fluoxetine and higher than that of quinidine. The results of this study imply that the risk of illicit drug interactions fluctuates so widely that unintentional fatal drug poisonings could occur.
\end{abstract}

Keywords: Methamphetamine; Designer Drug; GC-MS; TFA Derivatization; Interaction; Metabolism

\section{Introduction}

Designer drugs are a serious problem worldwide, especially among young people, and in some cases they have resulted in fatal poisoning [1-7]. New designer drugs are created by changing the molecular structure of an existing drug. This creates a compound with similar pharmacological effects, and is performed to circumvent existing drug laws. For example, 4-methoxymethamphetamine (4MMA) and 4-fluoromethamphetamine (4-FMA), which are 4-substituted psychoactive analogs of methamphetamine (MA), have emerged on the illicit drug market $[1,2$, 8-11]. Designer drugs such as illicit amphetamine-type

"Corresponding author. stimulants are often co-administered with other drugs in tablet, capsule, or powder form [12-17]. The emergence of new designer drugs and co-administration of drugs have made it difficult to discriminate controlled substances in forensic samples, and have increased drug-related problems.

We previously reported a method for distinguishing currently controlled substances, such as MA, 4-MMA, and 4-FMA, from other uncontrolled 4-substituted MAs, including 4-chloromethamphetamine (4-CMA), 4-bromomethamphetamine (4-BMA), 4-iodomethamphetamine (4-IMA), and 4-nitromethamphetamine (4-NMA) [18]. As a way to circumvent existing drug laws, production and subsequent abuse of 4-CMA, 4-BMA and 4-NMA is expected in future because details of their psychotomi- 
metic properties and synthetic processes are easy to obtain online [19]. Additionally, like 4-iodo-2, 5-dimethoxy-phenethylamine (2C-I) and 4-iodo-2, 5-dimethoxyamphetamine (DOI), which have been widely abused as designer drugs, 4-IMA also has a 4-iodinated aromatic part. Therefore, it is expected that these 4-substituted analogs of MA will be encountered in forensic cases in the future.

In general, the most common types of metabolic drugdrug interactions are inhibition and induction of drug metabolizing enzymes. These interactions can increase or decrease drug exposure when two or more drugs are co-administered, and this can enhance drug toxicity [20]. However, there is little information available about the ability of designer drugs to inhibit the metabolism of the other drugs administered. Evaluation of the potential risk of metabolic drug-drug interactions is important. In this investigation, in vitro experiments with human metabolic enzymes were used to study the major metabolites of six 4-substituted MAs and their ability to inhibit the metabolism of MA.

\section{Materials and Methods}

\subsection{Chemicals and Reagents}

MA was purchased from Dainippon Pharmaceutical (Osaka, Japan), and 4-MMA and p-hydroxymethamphetamine (OHMA) were obtained from Sigma-Aldrich (St Louis, MO). Amphetamine (AP) was donated by the Ministry of Health, Labour and Welfare, Japan. 4-Chlorophenylacetone, 4-bromophenylacetone, and sodium cyanoborohydride were purchased from Kanto Chemical Co., Inc. (Tokyo, Japan). 4-Fluorophenylacetone, 4-nitrophenylacetone, 4-iodophenylacetic acid, and acetic anhydride were purchased from Wako Pure Chemical Industries Ltd. (Osaka, Japan). Trifluoroacetic anhydride (TFA) was obtained from Nacalai Tesque (Kyoto, Japan). Ammonium acetate was purchased from Katayama Chemical Industries Co., Ltd. (Osaka, Japan). All other chemicals were purchased from commercial sources and used without further purification.

Pooled human liver microsomes (HLM, BD UltraPool $^{\mathrm{TM}}$ HLM 150), Solution A (31 mmol/L NADP ${ }^{+}, 66$ $\mathrm{mmol} / \mathrm{L}$ glucose-6-phosphate, and $66 \mathrm{mmol} / \mathrm{L} \mathrm{MgCl}_{2}$ in water) and Solution B (40 U/mL glucose-6-phosphate dehydrogenase in $5 \mathrm{mmol} / \mathrm{L}$ sodium citrate buffer) for a $\mathrm{NADPH}$ regenerating system, and $0.5 \mathrm{~mol} / \mathrm{L}$ potassium phosphate buffer ( $\mathrm{pH}$ 7.4) were supplied by BD Biosciences (San Jose, CA). Microsomes from baculovirusinfected insect cells (expressing CYP1A2, CYP2C9, CYP2C19, CYP2D6, CYP3A4 and CYP3A5) were also obtained from the BD Biosciences.

\subsection{Synthesis of Standards}

Five 4-substituted analogs of MA and five 4-substituted analogs of AP were synthesized. They were obtained by reductive amination of 4-substituted phenylacetones in methanol with sodium cyanoborohydride [21]. The synthesized compounds were ascertained by matrix-assisted laser desorption/ionization time-of-flight mass spectrometry (MALDI-TOF/MS) or liquid chromatographyelectrospray ionization-time-of-flight mass spectrometry (LCESI-TOF-MS).

4-FMA: A mixture of 4-fluorophenylacetone (1 mmol), $40 \%$ methylamine methanol solution $(1.5 \mathrm{mmol})$, acetic acid $(2 \mathrm{mmol})$, and sodium cyanoborohydride $(1.5 \mathrm{mmol})$ was stirred overnight at room temperature in methanol. After the reaction, methanol was evaporated in vacuo and $2 \mathrm{M}$ hydrochloric acid solution was added to the residue. The aqueous solution was stirred for $0.5 \mathrm{~h}$ at room temperature, after which $1 \mathrm{M}$ aqueous sodium hydroxide was added to make the solution alkaline. The aqueous layer was extracted with dichloromethane, and the combined organic layer was washed with brine, dried over anhydrous sodium sulfate, and concentrated. Ethereal hydrochloric acid was added to the residue. The solution was allowed to stand at $5^{\circ} \mathrm{C}$ until precipitation occurred. The precipitate was then filtered off, and the residue was washed with pre-chilled diethyl ether and air dried to afford 4-FMA hydrochloride. The protonated molecular ion of 4-FMA, $[\mathrm{MH}]^{+}$, was observed at $\mathrm{m} / \mathrm{z} 168.224$ by MALDI-TOF/MS.

4-CMA: The same procedure as that for 4-FMA hydrochloride was carried out for 4-chlorophenylacetone (1 mmol), which was used as the starting material to obtain 4-CMA hydrochloride. The protonated molecular ion of 4-CMA, $[\mathrm{MH}]^{+}$, was observed at $m / z \quad 184.156 / 186.122$ by MALDI-TOF/MS.

4-BMA: The same procedure as that for 4-FMA hydrochloride was carried out for 4-bromophenylacetone (1 mmol), which was used as the starting material to obtain 4-BMA hydrochloride. The protonated molecular ion of 4-BMA, $[\mathrm{MH}]^{+}$, was observed at $\mathrm{m} / \mathrm{z} 228.115 / 230.085$ by MALDI-TOF/MS.

4-IMA: 4-iodophenylacetone was prepared by refluxing 4-iodophenylacetic acid $(2 \mathrm{mmol})$ and acetic anhydride with pyridine [22]. The same procedure as that for 4-FMA hydrochloride was performed for 4-iodophenylacetone, which was used as the starting material to obtain 4-IMA hydrochloride. The protonated molecular ion of 4 -IMA, $[\mathrm{MH}]^{+}$, was observed at $\mathrm{m} / \mathrm{z} 276.130$ by MALDI-TOF/MS.

4-NMA: The same procedure as that for 4-FMA hydrochloride was carried out for 4-nitrophenylacetone (1 mmol), which was used as the starting material to obtain 4-NMA hydrochloride. The protonated molecular ion of 4-NMA, $[\mathrm{MH}]^{+}$, was observed at $\mathrm{m} / \mathrm{z} 195.059$ by MALDI-TOF/MS.

Five 4-substituted analogs of AP, 4-Fluoroampheta- 
mine (4-FAP), 4-Chloroamphetamine (4-CAP), 4-Bromoamphetamine (4-BAP), 4-Iodoamphetamine (4-IAP) and 4-Nitroamphetamine (4-NAP), were synthesized by the same procedures as above reported 4-substitued MAs, but using ammonium acetate instead of methylamine. The protonated molecular ion $[\mathrm{MH}]^{+}$of 4-FAP, 4-CAP, 4BAP, 4-IAP and 4-NAP were observed at $\mathrm{m} / \mathrm{z}$ 154.10, $\mathrm{m} / \mathrm{z}$ 170.07/172.07, $\mathrm{m} / \mathrm{z} 214.02 / 216.02, \mathrm{~m} / \mathrm{z} 262.01$ and $\mathrm{m} / \mathrm{z} 181.10$ by LC-ESI-TOF-MS, respectively.

\subsection{Microsomal Incubation and Workup for Metabolism Experiments}

Incubation mixtures (final volume: $100 \mu \mathrm{L}$ for HLM, 200 $\mu \mathrm{L}$ for CYP1A2, CYP2C9, CYP2C19, CYP2D6, CYP3A4, and CYP3A5) consisted of $0.1 \mathrm{~mol} / \mathrm{L}$ potassium phosphate buffer (pH 7.4), $1.55 \mathrm{mmol} / \mathrm{L} \mathrm{NADP}^{+}, 3.3$ $\mathrm{mmol} / \mathrm{L}$ glucose 6-phosphate, $3.3 \mathrm{mmol} / \mathrm{L} \mathrm{MgCl}_{2}$ and 0.4 $\mathrm{U} / \mathrm{mL}$ glucose-6-phosphate dehydrogenase, and the substrate. The substrate was either MA (final concentration: $2,5,10,20,50,100,200,500,1000$ or $1500 \mu \mathrm{mol} / \mathrm{L}$ in water) or a 4-substituted MA (4-FMA, 4-CMA, 4-BMA, 4-IMA, 4-NMA, 4-MMA; final concentration $1 \mathrm{mmol} / \mathrm{L}$ in water). The mixtures were incubated at $37^{\circ} \mathrm{C}$. Reactions were started by adding ice-cold microsomes (final concentration: $2 \mathrm{mg} / \mathrm{mL}$ for HLM, $40 \mathrm{pmol} / \mathrm{mL}$ for CYP1A2, CYP2C19, and CYP2D6, $80 \mathrm{pmol} / \mathrm{mL}$ for CYP2C9, CYP3A4, and CYP3A5) and terminated with $200 \mu \mathrm{L}$ of methanol after $30 \mathrm{~min}$ of incubation. After termination, the samples were placed on wet ice and centrifuged. The supernatants were transferred to clean test tubes, and $600 \mathrm{~mL}$ of carbonate-bicarbonate buffer (pH 9.8) and $100 \mu \mathrm{L}$ of $0.92 \mu \mathrm{mol} / \mathrm{L} N$-butylbenzylamine methanolic (internal standard) were added. Each supernatant was extracted three times with $1 \mathrm{~mL}$ of 2-propanol-chloroform $(1: 3 ; \mathrm{v} / \mathrm{v})$. The combined organic layer was transferred into a glass flask and $200 \mu \mathrm{L}$ of 0.24 $\mathrm{mol} / \mathrm{L}$ methanolic $\mathrm{HCl}$ was added, and the sample was evaporated to dryness under a stream of nitrogen. The residue was subjected to TFA-derivatization (Section 2.5), and then dissolved in 100 or $1000 \mu \mathrm{L}$ of ethyl acetate. An aliquot $(1 \mu \mathrm{L})$ of the derivatized sample was injected into the gas chromatography-mass spectrometry (GC-MS) system.

\subsection{Microsomal Incubations for Inhibition Studies}

Mixtures (final volume: $200 \mathrm{~mL}, n=3$ ) containing 0.1 $\mathrm{mol} / \mathrm{L}$ potassium phosphate buffer $(\mathrm{pH} 7.4), 1.55 \mathrm{mmol} / \mathrm{L}$ $\mathrm{NADP}^{+}, 3.3 \mathrm{mmol} / \mathrm{L}$ glucose 6 -phosphate, $3.3 \mathrm{mmol} / \mathrm{L}$ $\mathrm{MgCl}_{2}, 0.4 \mathrm{U} / \mathrm{mL}$ glucose-6-phosphate dehydrogenase, and substrate MA (final concentration: $20 \mathrm{mmol} / \mathrm{L}$ ) were incubated in the presence or absence of a potential inhibitor (4-FMA, 4-CMA, 4-BMA, 4-IMA, 4-NMA or
4-MMA). The final concentration of the inhibitor was 0.3 , $1,3,10$ or $30 \mu \mathrm{mol} / \mathrm{L}$. Alternatively, the mixture was incubated with a well-known inhibitor (fluoxetine or quinidine) with a final inhibitor concentration of $0.3,1,3$, 10 or $30 \mu \mathrm{mol} / \mathrm{L}$ for fluoxetine and $0.3,1,3,10$ or 30 $\mathrm{nmol} / \mathrm{L}$ for quinidine. The mixtures were incubated at $37^{\circ} \mathrm{C}$ for $30 \mathrm{~min}$. The methanol volume fraction was below $0.3 \%$ in all samples. Reactions were started by adding ice-cold microsomes containing CYP2D6 (final concentration: $40 \mathrm{pmol} / \mathrm{mL}$ ) and terminated with $200 \mu \mathrm{L}$ of methanol. After termination, the sample workup was as described in Section 2.3, and the samples were analyzed by GC-MS.

\subsection{GC-MS}

GC-MS analysis of MA, AP, OHMA and the six 4-substituted MAs and 4-substituted APs was performed as follows. A Shimadzu 17-A gas chromatograph equipped with a QP-5050A mass spectrometer (Kyoto, Japan) was operated under the following conditions: ionization mode, electron ionization; ionization energy, $70 \mathrm{eV}$; carrier gas, helium; flow rate, $1.9 \mathrm{~mL} / \mathrm{min}$; capillary column, DB5MS (Agilent, Santa Clara, CA, $30 \mathrm{~m} \times 0.25 \mathrm{~mm}$ i.d., 0.25 $\mu \mathrm{m}$ film thickness); injector temperature, $200^{\circ} \mathrm{C}$; injection mode, splitless; and scan range, $\mathrm{m} / \mathrm{z} 35-375$. The oven temperature was held at $60^{\circ} \mathrm{C}$ for $2 \mathrm{~min}$, then increased to $250^{\circ} \mathrm{C}$ at $20^{\circ} \mathrm{C} / \mathrm{min}$ and held for $3 \mathrm{~min}$.

TFA derivatives of the analytes were prepared by adding $100 \mu \mathrm{L}$ of TFA and $100 \mu \mathrm{L}$ of ethyl acetate to the sample, after which the mixture was reacted at $65^{\circ} \mathrm{C}$ for $10 \mathrm{~min}$. The reaction mixture was carefully evaporated and dried under a gentle nitrogen stream, and then reconstituted in 100 or $1000 \mu \mathrm{L}$ of ethyl acetate. Subsequently, $1 \mu \mathrm{L}$ aliquots were automatically injected into the GCMS system within $3 \mathrm{~h}$ of reconstitution [23].

For quantification, the following target ions $(\mathrm{m} / \mathrm{z})$ were used in selected ion monitoring mode: $\mathrm{m} / \mathrm{z} 118$ for AP, $\mathrm{m} / \mathrm{z} 154$ for OHMA, and $\mathrm{m} / \mathrm{z} 91$ for the internal standard (IS) $N$-butylbenzylamine. Calibration curves for AP and OHMA were constructed based on the ion peak-area ratio of internal standard to AP or OHMA from $100 \mu \mathrm{L}$ (final concentration of $0.01,0.2,0.4,0.6,0.8$ or $1 \mu \mathrm{mol} / \mathrm{L}$ ) or $1000 \mu \mathrm{L}$ (final concentration of $0.6,4,8$ or $12 \mu \mathrm{mol} / \mathrm{L}$ ) samples. Good linearity was confirmed for all data.

To examine the impact of the in vitro incubation matrix, inactivated incubation mixtures spiked with blank water or known concentrations (sample volume of 100 $\mu \mathrm{L}$, final concentration of $0.01,0.1$ or $1 \mu \mathrm{mol} / \mathrm{L}$ in water; sample volume of $1000 \mu \mathrm{L}$, final concentration of $0.1,1$ or $10 \mu \mathrm{mol} / \mathrm{L}$ in water) of a mixture of AP and OHMA were extracted as described in Section 2.3. The obtained calibration curves were virtually the same as those for quantification. The analysis results for inactivated incubation mixtures spiked with the mixture of AP and 
OHMA showed there was no interference from the in vitro incubation matrix (Table 1 and Figure 1).

\subsection{Kinetics}

The effects of the CYP2D6 protein content and incubation time were evaluated to obtain the optimum conditions for linearity of the metabolic results. The resulting conditions for the kinetics study were a $40 \mathrm{pmol} / \mathrm{mL}$ protein concentration in the microsomes and a $30 \mathrm{~min}$ incubation at $37^{\circ} \mathrm{C}$. Substrate MA at a final concentration of $2,5,10,20,50,100,200,500,1000$ or $1500 \mu \mathrm{mol} / \mathrm{L}$ was used for the kinetic study. Kinetic data were analyzed by the Michaelis-Menten equation $\left(v=V_{\max }[S] /\right.$ $\left.\left(K_{m}+[S]\right)\right)$ and Hanes-Woolf equations $([S] / v=$ $\left.1 / V_{\max }[S]+K_{m} / V_{\max }\right)$, where $v$ is the initial reaction velocity, $V_{\max }$ the maximal reaction velocity, $K_{m}$ the Michaelis constant, and $[S]$ is the substrate concentration. $I C_{50}$ values were calculated according to the following Equation (1):

$$
\mathrm{IC}_{50}=10^{[\log (A / B) \times(50-C) /(D-C)+\log B]}
$$

Table 1. Validation data for quantitative analysis of the incubation matrix spiked with AP and OHMA by GC-MS after determination of TFA derivatization. The results are based on mass chromatograms (SIM mode) obtained with a sample volume of $100 \mathrm{~mL}$ or $1000 \mathrm{~mL}$.

\begin{tabular}{|c|c|c|c|c|c|c|c|c|}
\hline \multirow{2}{*}{$\begin{array}{l}\text { Sample volume } \\
\text { for GC/MS } \\
\text { analysis }\end{array}$} & \multirow{2}{*}{ Compound } & \multirow{2}{*}{$\begin{array}{l}\text { Correlation } \\
\text { coefficient }\end{array}$} & \multicolumn{3}{|c|}{ Intraday $\mathrm{CV}(\%)^{\mathrm{a}}$} & \multicolumn{3}{|c|}{ Interday $\mathrm{CV}(\%)^{\mathrm{a}}$} \\
\hline & & & $0.01 \mu \mathrm{mol} / \mathrm{L}$ & $0.1 \mu \mathrm{mol} / \mathrm{L}$ & $1 \mu \mathrm{mol} / \mathrm{L}$ & $0.01 \mu \mathrm{mol} / \mathrm{L}$ & $0.1 \mu \mathrm{mol} / \mathrm{L}$ & $1 \mu \mathrm{mol} / \mathrm{L}$ \\
\hline \multirow{3}{*}{$100 \mu \mathrm{L}$} & $\mathrm{AP}^{\mathrm{b}}$ & 0.9999 & 3.1 & 5.9 & 0.9 & 3.3 & 2.6 & 8.2 \\
\hline & OHMA $^{\mathrm{c}}$ & 0.9993 & 17.9 & 9.9 & 15.4 & 10.4 & 14.8 & 25.1 \\
\hline & & & $0.1 \mu \mathrm{mol} / \mathrm{L}$ & $1 \mu \mathrm{mol} / \mathrm{L}$ & $10 \mu \mathrm{mol} / \mathrm{L}$ & $0.1 \mu \mathrm{mol} / \mathrm{L}$ & $1 \mu \mathrm{mol} / \mathrm{L}$ & $10 \mu \mathrm{mol} / \mathrm{L}$ \\
\hline \multirow{2}{*}{$1000 \mu \mathrm{L}$} & $\mathrm{AP}^{\mathrm{b}}$ & 0.9999 & 12.1 & 2.3 & 2.7 & 7.5 & 6.1 & 2.6 \\
\hline & $\mathrm{OHMA}^{\mathrm{c}}$ & 0.9991 & 20.3 & 8.1 & 4.6 & 4.8 & 9.2 & 5.6 \\
\hline
\end{tabular}

${ }^{\mathrm{a}}$ Each value was obtained from three determinations, ${ }^{\mathrm{b}}$ The peak area of the base peak ion at $\mathrm{m} / \mathrm{z} 118$ was used, ${ }^{\mathrm{c}} \mathrm{The}$ peak area of the base peak ion at $\mathrm{m} / \mathrm{z} 154$ was used.

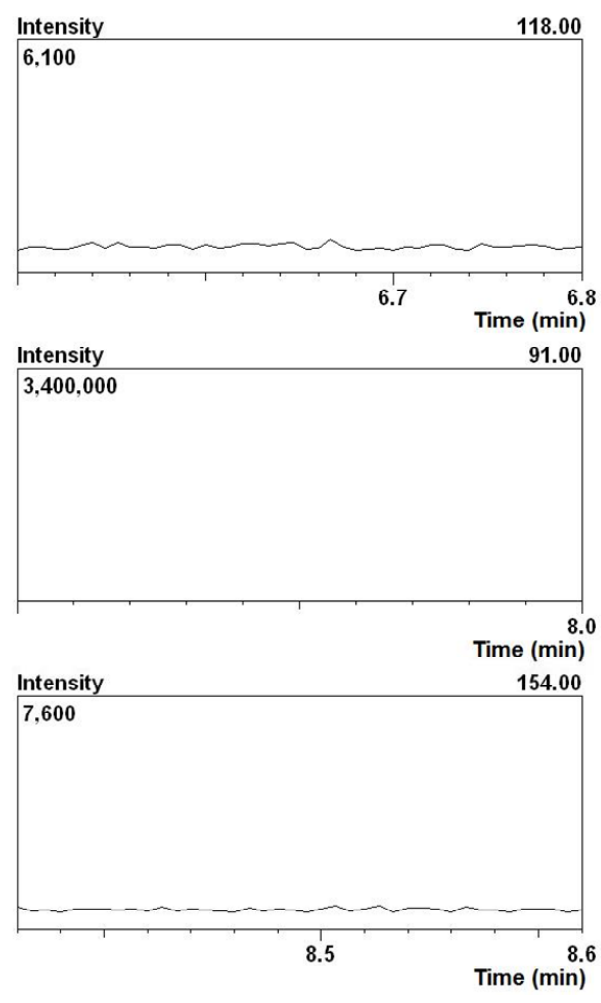

(a)
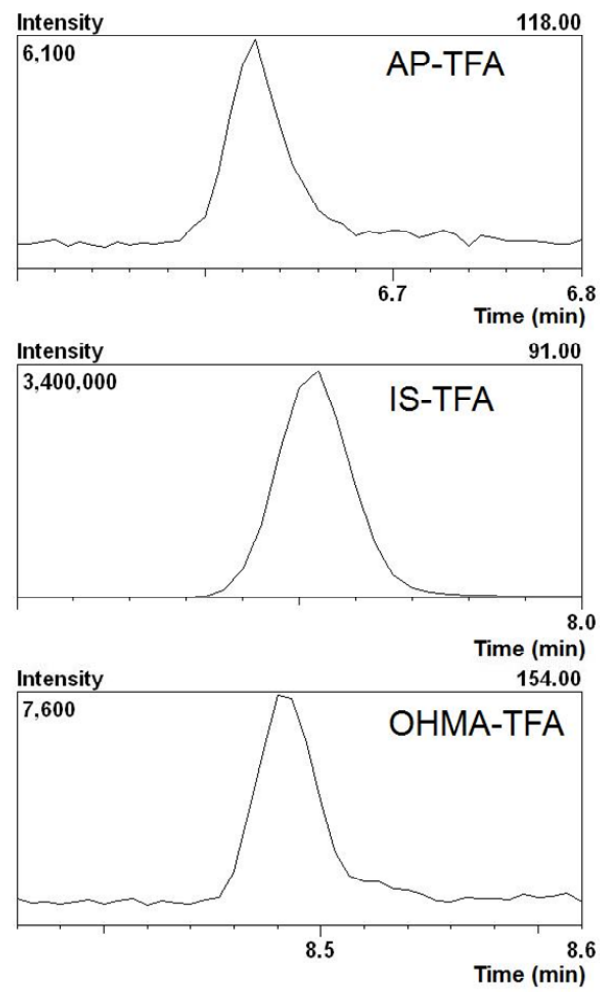

(b)

Figure 1. The mass chromatogram (SIM mode) of blank incubation matrix extract (a) and incubation matrix spiked with each analyte (final concentration of $0.01 \mu \mathrm{mol} / \mathrm{L}$ ) and the IS (b). 
where $A$ and $B$ are the higher and lower concentrations near $50 \%$ inhibition, respectively; and $C$ and $D$ are the percentages of control $B$ and $A$, respectively.

\section{Results and Discussion}

\subsection{In Vitro Metabolism of MA and 4-Substituted MAs}

MA was incubated with recombinant CYP1A2, CYP2C9, CYP2C19, CYP2D6, CYP3A4, CYP3A5 and HLM, and the main metabolites of MA, AP and OHMA, were formed (Figure 2). The production rates of the metabolites differed greatly depending on the enzyme (Table 2). With all of the enzymes tested, AP production from MA was greater than OHMA production. Therefore, $N$-demethylation of MA was superior to $p$-hydroxylation with these enzymes. Among the CYP isozymes tested, CYP2D6 was the dominant contributor to MA metabolism. Similar findings were reported by Kuwayama et al. and Lin et al., who found that CYP2D6 was the main enzyme that metabolized 3,4-methylenedioxymethamphetamine (MDMA) $[24,25]$.

4-FMA，4-CMA，4-BMA，4-IMA，4-NMA, and 4MMA were incubated independently with CYP2D6. Metabolites from $\mathrm{N}$-demethylation of 4-FMA, 4-CMA, 4BMA, 4-IMA and 4-NMA, and from $O$-demethylation of 4-MMA were detected (Figures 3 and 4). The results suggest that when any of these six 4-substituted MAs are taken, these metabolites will be present in human body fluids and tissues obtained from the user. This study using CYP2D6 and HLM showed that 4-MMA was metabolized mainly by $O$-demethylation, which agrees with the results of Staack et al. [8].

The production rates of the main metabolites of MA, AP and OHMA, were measured at various MA concentrations using microsomes from cells that stably express human CYP2D6, which was the dominant contributor to the metabolism of MA. The curves for the two main metabolites were fitted to the Michaelis-Menten equation (Figure 5). The $K_{m}$ values for MA $N$-demethylation (Figure 5(a)) and $p$-hydroxylation (Figure 5(b)) were estimated to be 30 and $70 \mu \mathrm{mol} / \mathrm{L}$, respectively. The $V_{\max }$ values for MA $N$-demethylation and $p$-hydroxylation were 5.8 and $0.45 \mathrm{pmol} /(\min \times \mathrm{pmol})$, respectively.

\subsection{Comparison of Inhibitory Activity of the Six 4-Substituted MAs toward CYP2D6- Mediated Metabolism of MA}

To determine the $\mathrm{IC}_{50}$ values for CYP2D6, the percentage values of AP and OHMA production activity were plotted against the concentrations for each inhibitor (Figures 6 and 7). The percentage production activities were calculated by comparison with production activities for AP and OHMA production without inhibitor. The results

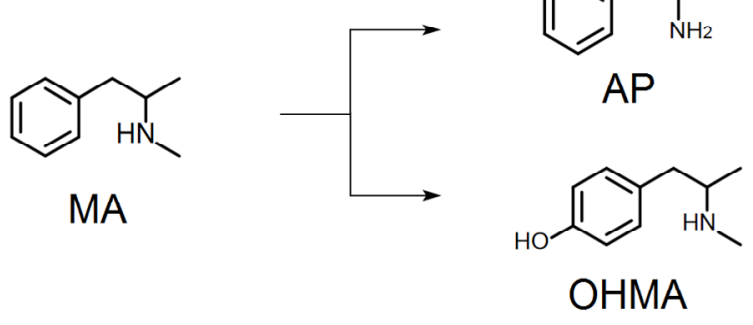

Figure 2. Metabolism of methamphetamine (MA) to amphetamine (AP) and p-hydroxymethamphetamine (OHMA).

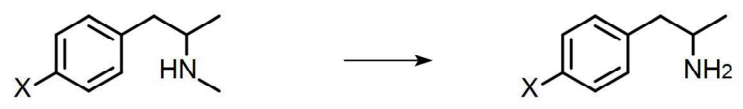

4-substituted MAs

4-substituted APs

$\left(\mathrm{X}=\mathrm{F}, \mathrm{Cl}, \mathrm{Br}, \mathrm{I}, \mathrm{NO}_{2}\right)$

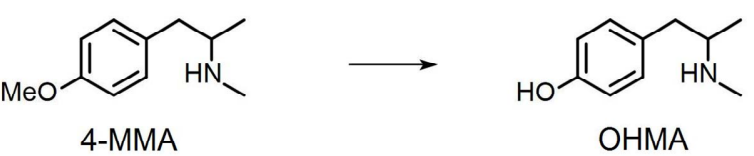

Figure 3. Metabolism of 4-substituted methamphetamines (4-MAs) and 4-methoxymethamphetamine (4-MMA) to substituted amphetamines (4-APs) and p-hydroxymethamphetamine (OHMA), respectively.

Table 2. Metabolism of methamphetamine $(1 \mathrm{mmol} / \mathrm{L})$ with various enzymes.

\begin{tabular}{ccc}
\hline \multirow{2}{*}{ Metabolic Enzyme } & \multicolumn{2}{c}{$\begin{array}{c}\text { Production Rate of Metabolite } \\
{\left[\mathrm{pmol} /\left(\mathrm{min} \times \mathrm{pmol} \mathrm{P}^{\mathrm{a}}\right)\right]^{\mathrm{a}}}\end{array}$} \\
\cline { 2 - 3 } & \multicolumn{1}{c}{ AP } & OHMA \\
\hline CYP1A2 & $0.62 \pm 0.05$ & $0.028 \pm 0.006$ \\
CYP2C9 & $0.15 \pm 0.05$ & $0.022 \pm 0.006$ \\
CYP2C19 & $0.86 \pm 0.13$ & $0.27 \pm 0.05$ \\
CYP2D6 & $5.8 \pm 0.9$ & $0.48 \pm 0.13$ \\
CYP3A4 & $0.11 \pm 0.01$ & $0.043 \pm 0.01$ \\
CYP3A5 & $0.089 \pm 0.024$ & $0.027 \pm 0.009$ \\
HLM & $0.14 \pm 0.02$ & $0.018 \pm 0.003$ \\
\hline
\end{tabular}

${ }^{\mathrm{a}}$ Each value represents the mean \pm SD from three independent experiments.

showed that the $\mathrm{IC}_{50}$ values against $\mathrm{AP}$ production from MA decreased in the following order: quinidine $>4$-IMA $>$ fluoxetine $>4$-BMA $>4$-CMA $>4$-MMA $>4$-FMA $>$ 4-NMA. The same trend was observed for the $\mathrm{IC}_{50}$ values against OHMA production from MA, except for the $\mathrm{IC}_{50}$ of 4-MMA. In the profile for inhibition of CYP2D6 by 4-MMA, OHMA production from MA increased at a rate almost proportional to the amount of 4-MMA added. Therefore, the effect of 4-MMA on OHMA formation from MA with CYP2D6 was not included in further analysis of the trend. The profile for inhibition of 

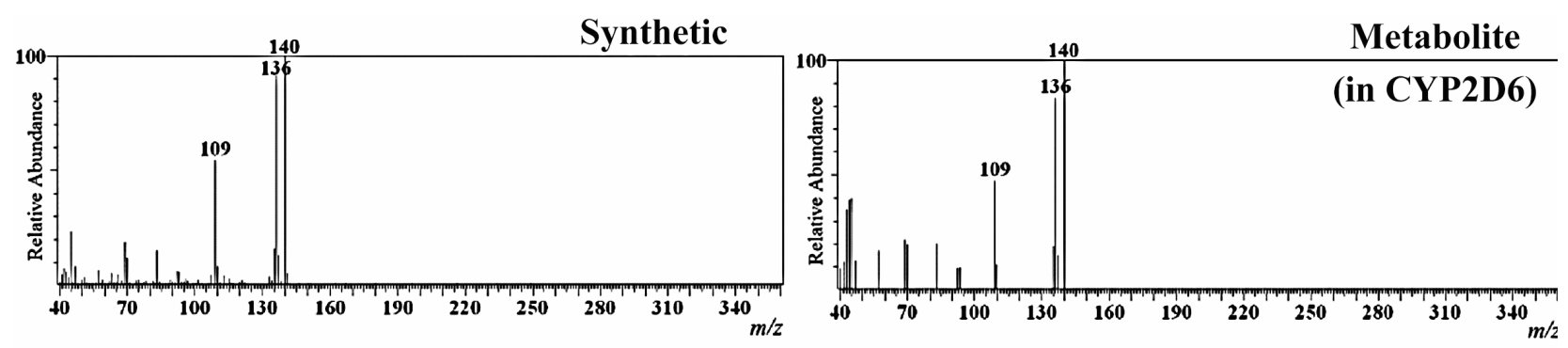

4-FAP-TFA (RI:1312)
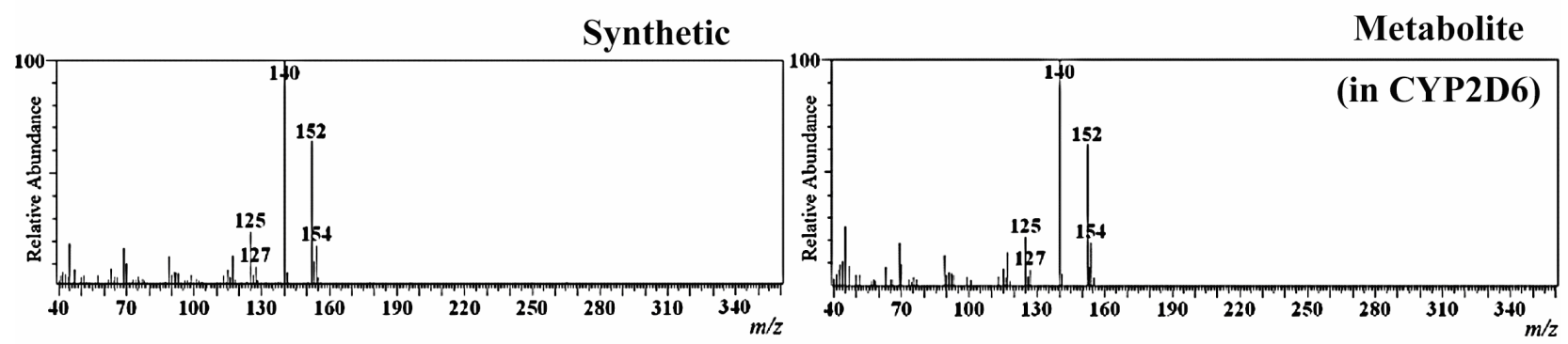

4-CAP-TFA (RI:1492)

Synthetic
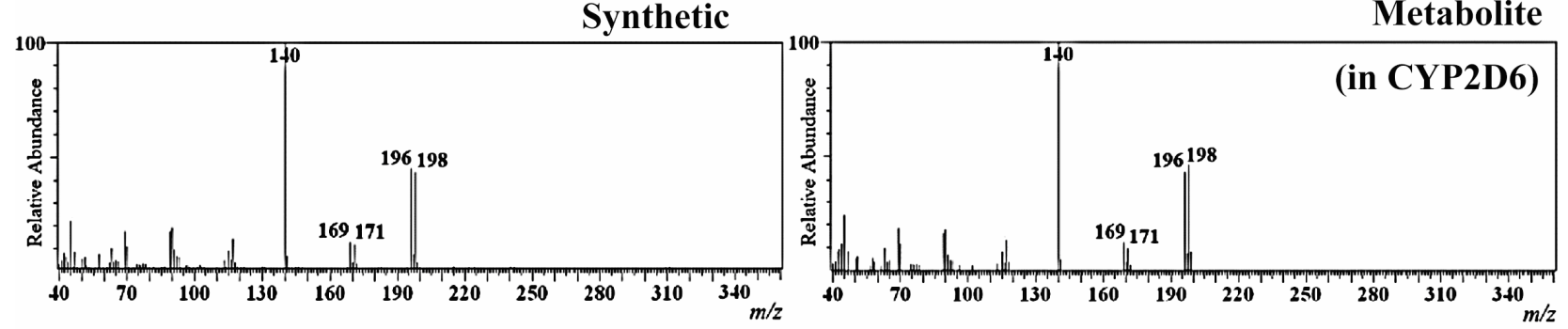

\section{4-BAP-TFA (RI:1585)}

Synthetic
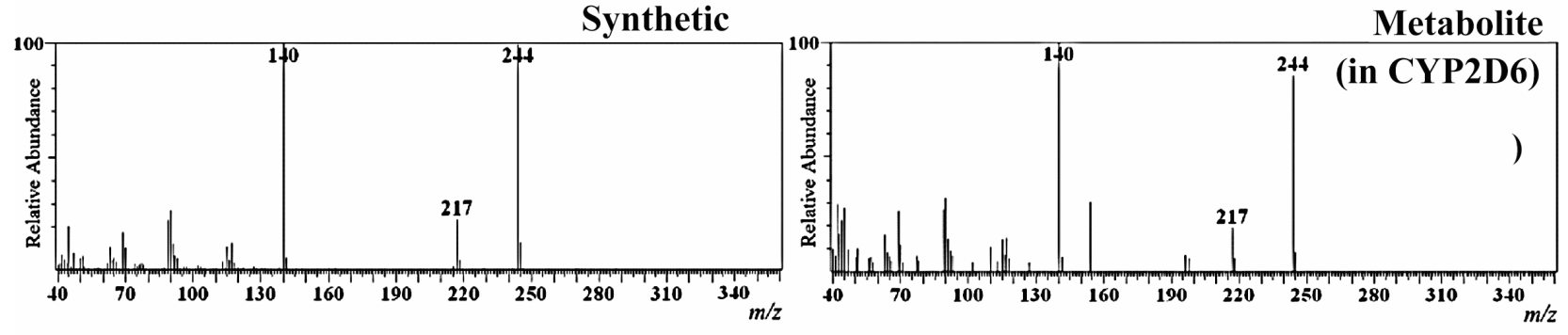

4-IAP-TFA (RI:1699)

Synthetic
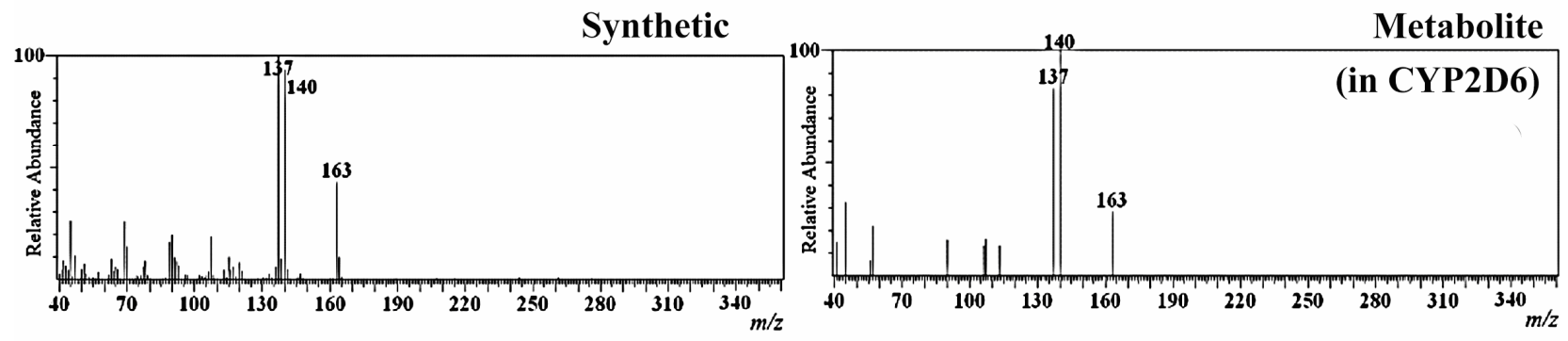

4-NAP-TFA (RI:1770)

Figure 4. EI mass spectra and retention indices (RI) of trifluoroacetic acid (TFA) derivatized 4-substituted analogs of amphetamine (AP) produced by synthesis or from metabolism of the corresponding substituted MA with CYP2D6. 


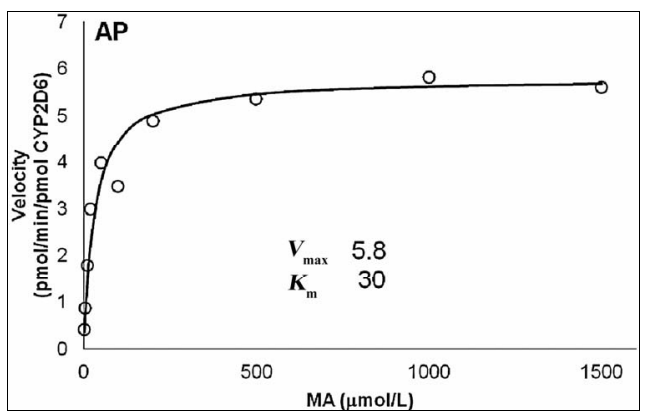

(a)

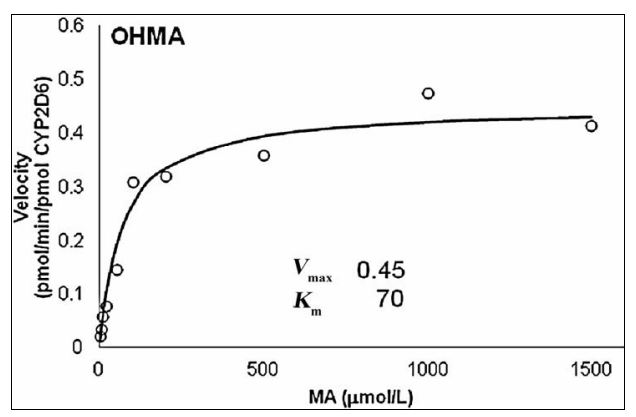

(b)

Figure 5. Michaelis-Menten plot for $N$-demethylation (a) and $p$-hydroxylation (b) of methamphetamine (MA) by recombinant CYP2D6. $V_{\max }$ and $K_{m}$ values were calculated from the Hanes-Woolf approximation of the Michaelis-Menten theory. The curves were fitted by nonlinear regression according to the Michaelis-Menten equation.
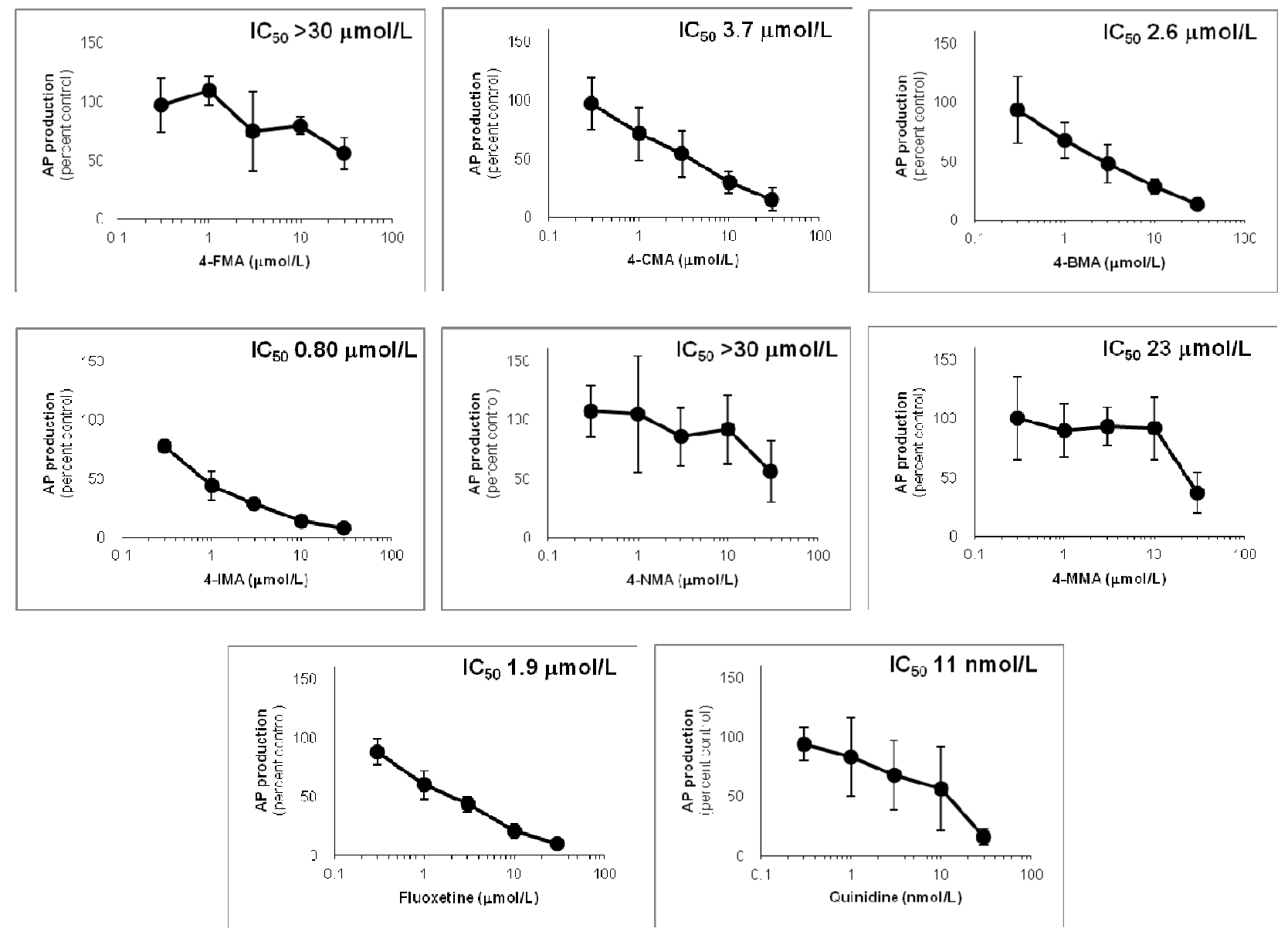

Figure 6. Inhibition of CYP2D6-mediated $N$-demethylation by 4-fluoromethamphetamine (4-FMA), 4-chloromethamphetamine (4-CMA), 4-bromomethamphetamine (4-BMA), 4-iodomethamphetamine (4-IMA), 4-nitromethamphetamine (4-NMA), 4-methoxymethamphetamine (4-MMA), fluoxetine and quinidine in human liver microsomes using methamphetamine (MA) as a substrate. The substrate concentration was lower than the $K_{m}$ (see Figure 5). Data points represent the average of three determinations per concentration and error bars represent standard deviations.

CYP2D6 by 4-MMA suggested that the production rate of OHMA from 4-MMA was much faster than the production rate of OHMA from MA.

The general trend was that the strength of inhibition of CYP2D6-mediated $N$-demethylation and $p$-hydroxylation increased as the halogen group of the 4-halogenated MA became larger. This structure-activity relationship is interesting because of its relevance to the $2 \mathrm{Cx}$ and DOx families of drugs, which have been widely abused. These drug families include 2C-I and DOI, which are 4-halo- 


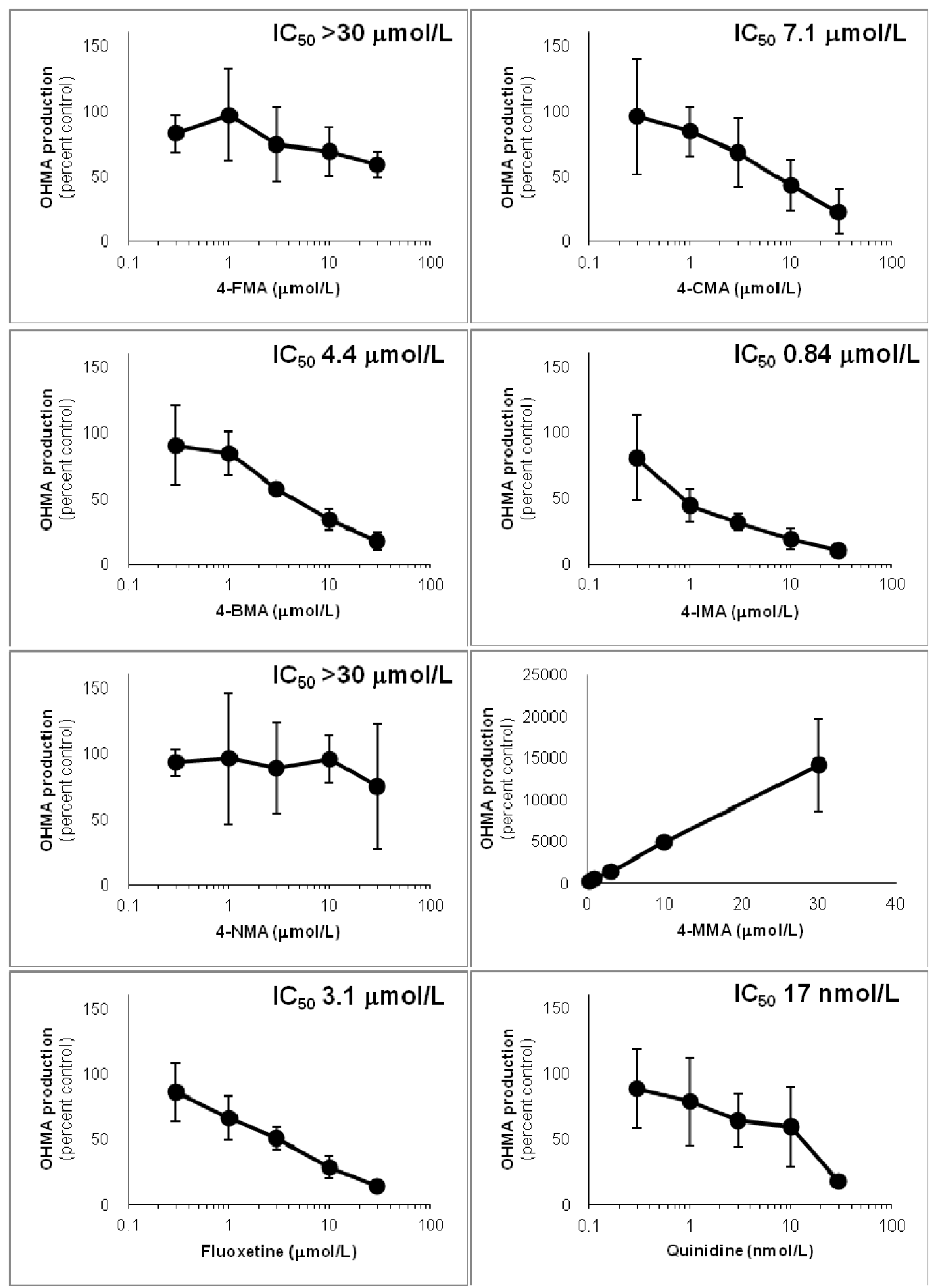

Figure 7. Inhibition of CYP2D6-mediated $p$-hydroxylation by 4-fluoromethamphetamine (4-FMA), 4-chloromethamphetamine (4-CMA), 4-bromomethamphetamine (4-BMA), 4-iodomethamphetamine (4-IMA), 4-nitromethamphetamine (4-NMA), 4-methoxymethamphetamine (4-MMA), fluoxetine and quinidine in human liver microsomes using methamphetamine (MA) as a substrate. Concentration scales of the inhibitors are logarithmic except for 4-MMA. The substrate concentration was lower than the $K_{m}$ (see Figure 5). Data points represent the average of three determinations per concentration and error bars represent standard deviations.

genated aromatic compounds like those studied here.

Comparison of the $\mathrm{IC}_{50}$ values of the compounds in this study, suggested that the strength of drug interactions could alter greatly with a change in the substituent. There- 
fore, designer drugs could interact with other drugs in an unexpected manner, and carry unknown risks and unforeseen consequences.

\section{Conclusion}

This study investigated the in vitro metabolism of six 4substituted MAs and their potential inhibition of MA metabolism using human metabolic enzymes by GC-MS after TFA derivatization. MA was mainly metabolized by CYP2D6, which catalyzed $N$-demethylation of 4-FMA, 4-CMA, 4-BMA, 4-IMA and 4-NMA, and catalyzed $O$ demethylation of 4-MMA. The $\mathrm{IC}_{50}$ values for the 4substituted MAs for CYP2D6-catalyzed AP and OHMA production from MA were, in descending order, 4-IMA > 4 -BMA $>4$-CMA $>4$-MMA $>4$-FMA $>4$-NMA. The $\mathrm{IC}_{50}$ of 4-MMA against OHMA production was the only exception to this trend. The $\mathrm{IC}_{50}$ values were between 0.80 and $>30 \mu \mathrm{mol} / \mathrm{L}$ for AP production and 0.84 and $>30 \mu \mathrm{mol} / \mathrm{L}$ for OHMA production. These results show that although amphetamine-type stimulants with similar chemical structures can be metabolized by the same metabolic enzymes, they interact with co-administered compounds to varying degrees. This suggests that the risk of illicit drug interactions fluctuates so widely that drug abusers could not be aware of the potential danger of these interactions.

\section{REFERENCES}

[1] J. Becker, P. Neis, J. Röhrich and S. Zörntlein, “A Fatal Paramethoxymethamphetamine Intoxication," Legal Medicine (Tokyo, Japan), Vol. 5, 2003, pp. S138-S141. doi:10.1016/S1344-6223(02)00096-2

[2] S. S. Johansen, A. C. Hansen, I. B. Müller, J. B. Lundemose and M. B. Franzmann, "Three Fatal Cases of PMA and PMMA Poisoning in Denmark," Journal of Analytical Toxicology, Vol. 27, No. 4, 2003, pp. 253-256.

[3] R. Dams, E. A. De Letter, K. A. Mortier, J. A. Cordonnier, W. E. Lambert, M. H. Piette, S. Van Calenbergh and A. P. De Leenheer, "Fatality Due to Combined Use of the Designer Drugs MDMA and PMA: A Distribution Study," Journal of Analytical Toxicology, Vol. 27, No. 5, 2003, pp. 318-322.

[4] E. A. De Letter, W. E. Lambert, M. P. Bouche, J. A. Cordonnier, J. F. Van Bocxlaer and M. H. Piette, "Postmortem Distribution of 3,4-Methylenedioxy- $N, N$-dimethyl-amphetamine (MDDM or MDDA) in a Fatal MDMA Overdose," International Journal of Legal Medicine, Vol. 121, No. 4, 2007, pp. 303-307. doi:10.1007/s00414-006-0094-x

[5] G. P. Dowling, E. T. McDonough and R. O. Bost, “"Eve' and 'Ecstasy'. A Report of Five Deaths Associated with the Use of MDEA and MDMA," The Journal of American Medical Association, Vol. 257, No. 12, 1987, pp. 16151617. doi:10.1001/jama.1987.03390120077027
[6] J. A. Henry, K. J. Jeffreys and S. Dawling, "Toxicity and Deaths from 3,4 Methylenedioxymethamphetamine ('Ecstasy')," Lancet, Vol. 340, No. 8816, 1992, pp. 384-387. doi:10.1016/0140-6736(92)91469-O

[7] S. Iwersen and A. Schmoldt, "Two Very Different Fatal Cases Associated with the Use of Methylenedioxyethylamphetamine (MDEA): Eve as Deadly as Adam," Journal of Toxicology-Clinical Toxicology, Vol. 34, No. 2, 1996, pp. 241-244. doi:10.3109/15563659609013778

[8] R. F. Staack, D. S. Theobald, L. D. Paul, D. Springer, T. Kraemer and H. H. Maurer, "Identification of Human Cytochrome P450 2D6 as Major Enzyme Involved in the $O$ Demethylation of the Designer Drug $p$-Methoxymethamphetamine," Drug Metabolism and Disposition, Vol. 32, No. 4, 2004, pp. 379-381. doi:10.1124/dmd.32.4.379

[9] K. Zaitsu, M. Katagi, T. Kamata, H. Kamata, N. Shima, H. Tsuchihashi, T. Hayashi, H. Kuroki and R. Matoba, "Determination of a Newly Encountered Designer Drug ' $p$-Methoxyethylamphetamine' and Its Metabolites," Forensic Science International, Vol. 177, No. 1, 2008, pp. 77-84. doi:10.1016/j.forsciint.2007.11.001

[10] P. Rösner, B. Quednow, U. Girreser and T. Junge, "Isomeric Fluoro-Methoxy-Phenylalkylamines: A New Series of Controlled-Substance Analogues (Designer Drugs)," Forensic Science International, Vol. 148, No. 2-3, 2005, pp. 143-156. doi:10.1016/i.forsciint.2004.05.003

[11] M. Nagashima, T. Seto, M. Takahashi, J. Suzuki and I. Yasuda, "Spectrum Data of the 3rd Governor-Designated Drugs and the Analyses of Uncontrolled Drugs Purchased April 2005-March 2006," Tokyo Metropolitan Institute of Public Health Annual Report (in Japanese), Vol. 57, 2006, pp. 109-113.

[12] J. C. Cole, M. Bailey, H. R. Sumnall, G. F. Wagstaff and L. A. King, "The Content of Ecstasy Tablets: Implications for the Study of Their Long-Term Effects," Addiction, Vol. 97, No. 12, 2002, pp. 1531-1536. doi:10.1046/j.1360-0443.2002.00222.x

[13] C. M. Milroy, J. C. Clark and A. R. W. Forrest, "Pathology of Deaths Associated with 'Ecstasy' and 'Eve' Misuse,” Journal of Clinical Pathology, Vol. 49, No. 2, 1996, pp. 149-153. doi:10.1136/jcp.49.2.149

[14] Y. Makino, S. Tanaka, S. Kurobane, M. Nakauchi, T. Terasaki and S. Ohta, "Profiling of Illegal AmphetamineType Stimulant Tablets in Japan," Journal of Health Science, Vol. 49, No. 2, 2003, pp. 129-137. doi:10.1248/jhs.49.129

[15] A. Camilleri, M. R. Johnston, M. Brennan, S. Davis and D. G. Caldicott, "Chemical Analysis of Four Capsules Containing the Controlled Substance Analogues 4-Methylmethcathinone, 2-Fluoromethamphetamine, Alpha-Phthalimidopropiophenone and N-Ethylcathinone," Forensic Science International, Vol. 197, No. 1-3, 2010, pp. 59-66. doi:10.1016/j.forsciint.2009.12.048

[16] F. Caudevilla-Gálligo, J. Riba, M. Ventura, D. González, M. Farré, M. J. Barbanoj and J. C. Bouso, "4-Bromo-2,5- 
dimethoxyphenethylamine (2C-B): Presence in the Recreational Drug Market in Spain, Pattern of use and Subjective Effects," Journal of Psychopharmacology, Vol. 26, No. 7, 2012, pp. 1026-1035. doi:10.1177/0269881111431752

[17] T. M. Brunt, M. W. Koeter, R. J. Niesink and W. van den Brink, "Linking the Pharmacological Content of Ecstasy Tablets to the Subjective Experiences of Drug Users," Psychopharmacology (Berl), Vol. 220, No. 4, 2012, pp. 751-762. doi:10.1007/s00213-011-2529-4

[18] M. Taniguchi, Y. Yamamoto and K. Nishi, "A Technique Combining Trifluoroacetyl Derivatization and Gas Chromatography-Mass Spectrometry to Distinguish Methamphetamine and Its 4-Substituted Analogs," Journal of Mass Spectrometry, Vol. 45, No. 12, 2010, pp. 1473-1476. doi:10.1002/jms.1851

[19] J. B. Ledgard, "A Laboratory History of Narcotics, Amphetamines and Derivatives," 2007.

[20] M. H. Beers and R. Berkow, "The Merck Manual," 17th Edition, Merck \& Co., Inc., Pennsylvania, 1999.

[21] R. F. Borch, M. D. Bernstein and H. D. Durst, "Cyanohy- dridoborate Anion as a Selective Reducing Agent," Journal of the American Chemical Society, Vol. 93, No. 12, 1971, pp. 2897-2904. doi:10.1021/ja00741a013

[22] R. S. Frank, "The Clandestine Drug Laboratory Situation in the United States," Journal of Forensic Sciences, Vol. 28, No. 1, 1983, pp. 18-31.

[23] T. Inoue, S. Suzuki and T. Niwaguchi, "Stability of Perfluoroacyl Derivatives of Methamphetamine and Its Metabolites," Eisei Kagaku (in Japanese), Vol. 29, No. 6, 1983, pp. 412-417. doi:10.1248/jhs1956.29.6 412

[24] K. Kuwayama, K. Tsujikawa, H. Miyaguchi, T. Kanamori, Y. T. Iwata and H. Inoue, "Interaction of 3,4-Methylenedioxymethamphetamine and Methamphetamine during Metabolism by in Vitro Human Metabolic Enzymes and in Rats," Journal of Forensic Sciences, Vol. 57, No. 4, 2011, pp. 1008-1013. doi:10.1111/j.1556-4029.2011.02039.x

[25] L. Y. Lin, E. W. Di Stefano, D. A. Schmitz, L. Hsu, S. W. Ellis, M. S. Lennard, G. T. Tucker and A. K. Cho, "Oxidation of Methamphetamine and Methylenedioxymethamphetamine by CYP2D6," Drug Metabolism and Disposition, Vol. 25, No. 9, 1997, pp. 1059-1064. 